\title{
Design Strategy of Rural Korean Residential Buildings in Yanbian Based on Sustainable Development
}

\author{
Ruiheng Sun ${ }^{1, a}$ \\ ${ }^{I}$ School of architecture and design, Changchun Institute of Technology, Chang Chun,JiLin,China \\ aemail:sunruiheng@ccit.edu.cn
}

\begin{abstract}
Taking Yanbian Rural Korean folk houses as the research object, through the investigation of the current situation of Yanbian Rural Korean folk houses, find out the shortcomings and problems. Combined with the geographical conditions, climate characteristics and the living customs of Korean residents, this paper puts forward the design strategy of sustainable development from the plane form, envelope structure, material use, indoor heating mode, new energy utilization and other aspects.
\end{abstract}

Keywords: Sustainable development, Yanbian area, Rural houses of Korean nationality, Design strategy

\section{INTRODUCTION}

Yanbian area is located in the east of Jilin Province (Fig. 1), within the range of $41^{\circ} 59^{\prime} \sim 44^{\circ} 30^{\prime} \mathrm{N}$ and $127^{\circ} 27^{\prime} \sim 131^{\circ} 18^{\prime}$ E. It belongs to the humid monsoon climate in the middle temperate zone, with obvious monsoon and four distinct seasons. Degree days $4267{ }^{\circ} \mathrm{C} \cdot \mathrm{D}[1]$. The population of Korean nationality in Yanbian is large and widely distributed, accounting for $37.7 \%$.

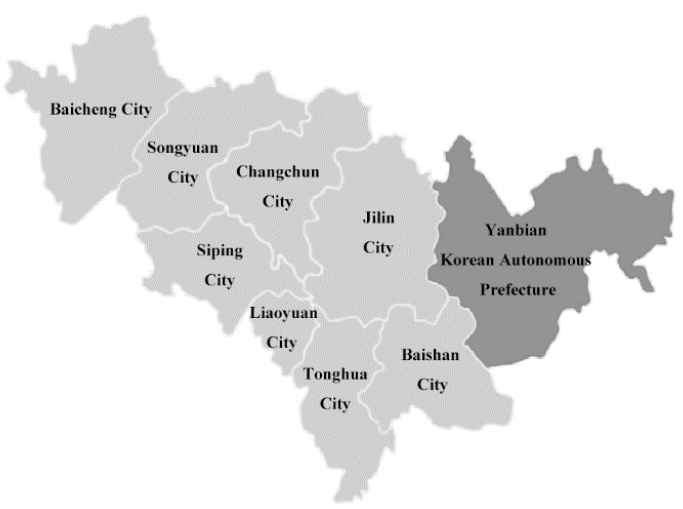

Figure 1. Geographical location map of Yanbian

\section{CHARACTERISTICS OF TRADITIONAL KOREAN RURAL HOUSES}

\subsection{Planning layout}

Different from the houses of Han nationality, the houses of Korean nationality do not strictly follow the direction of facing south, but are distributed along the direction of roads. Most of them are single buildings with determinant layout, and the roads and buildings are separated by small shrubs. Because the terrain of Yanbian area is mostly mountainous area, most Korean villages gather at the foot of the mountain or the flat land between the mountains, and are built according to the mountain situation. The number of households is less than ten, and more than dozens. The distance between villages is relatively close, and the scale is $3-5 \mathrm{~km}[2]$. The relationship between courtyard and architecture is divided into front courtyard, back courtyard and front and back courtyard, most of which are rectangular. 


\subsection{Architectural plan}

(1) The plane structure of Korean traditional dwellings is very characteristic, generally rectangular, and a few dwellings are L-shaped[3](Table 1).
(2) Two doors are set in the north-south direction of the house, which is convenient to lead to different areas of the yard; Opening windows along the length of the house; The house is built with brick or clay, with a height of $300-500 \mathrm{~mm}[4]$. The height of the platform is equal to the surface of the Kang.

Table 1. Plane types and characteristics of Korean folk houses

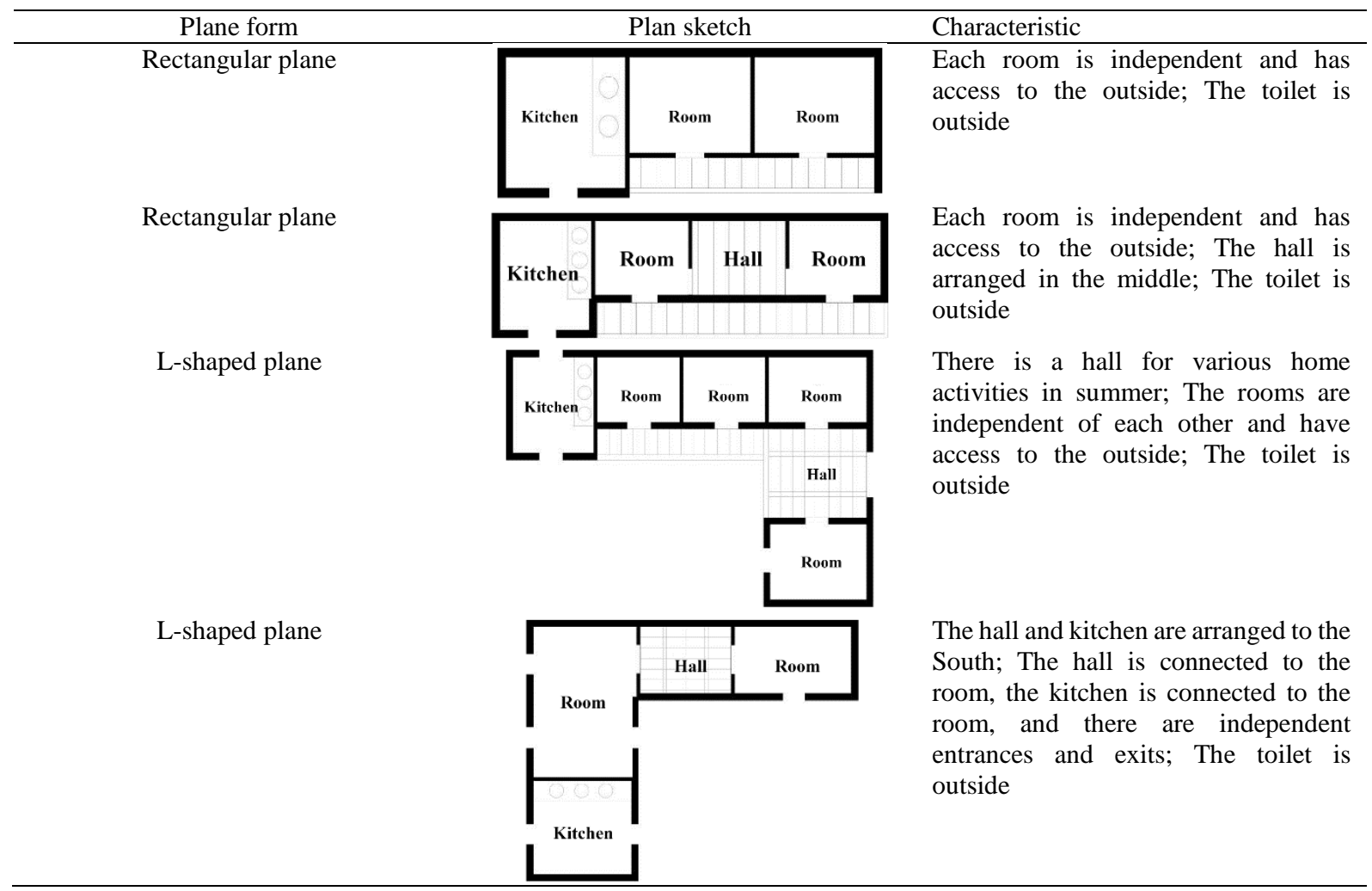

\subsection{Building facade}

There is a big difference between Korean traditional houses and Han traditional houses in the treatment of building facade. The roof usually adopts sloping roof, but the slope is gentle, the height of roof ridge is relatively low, and the proportion of flat doors and windows highlights the rising trend of the building. The exterior wall surface is painted white, with a gray thatched roof, which is very textural. The overall effect gives people a clean and elegant feeling. The roof adopts the four slope roof and is paved with thick straw covering, which is conducive to drainage. At the same time, it makes full use of the local materials and has a generous appearance. The local Han people's si'a style houses refer to the roof form of Korean traditional houses.(Fig. 2).

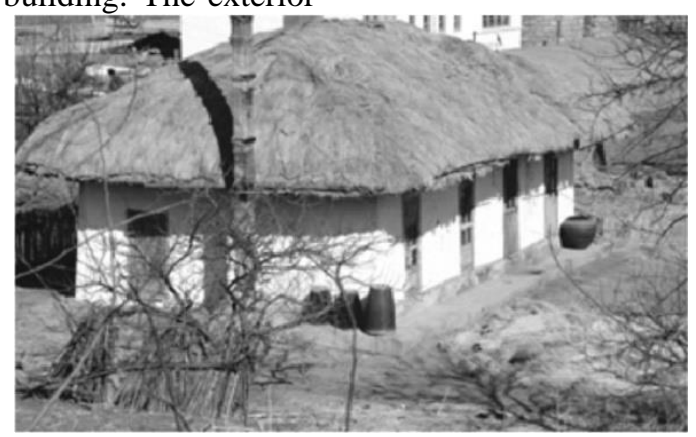

Figure 2. Appearance of traditional Korean dwellings 


\subsection{Architectural structure}

Traditional Korean houses are usually supported by wooden frames. In order to prevent water and moisture, it is necessary to build a $300 \mathrm{~mm}$ high platform with earth pad and then pile up with stone. There are two kinds of exterior walls: solid wall and hollow wall. The solid wall is supported by wood, mixed with wicker and straw rope, leveled with cement mortar, finished with lime, and filled with sand. It can also be made into hollow wall without sand filling. The interior wall is usually partition wall, generally lath wall. The doors and windows are sliding windows with large ratio of length to width, and the flat ratio is to increase the tall and straight feeling of the building. At the same time, the doors and windows can be used as entrance. Sloping roof is adopted as the roof form, and structural slope making is adopted, with gentle slope. The roof is paved with straw curtain or willow branches on the wooden supporting structure, and then plastered with mud as the bonding layer. Willow or straw with thickness of $300-500 \mathrm{~mm}$ is paved on the roof, and then bound and fixed with straw rope to resist wind and rain.
The winter in Yanbian is cold and long, especially in the rural houses in mountainous areas. The indoor warmth is directly related to people's living comfort. The traditional heating method of Korean rural houses has its own characteristics and advantages. The ground Kang is generally used. The floor is overhead and made into holes similar to the hot Kang. The brick floor is laid on it. These holes are connected with the cooking stove. When cooking and heating the stove, the heat source will heat the ground Kang through the holes. In this way, the heating for cooking and indoor heating can be saved at one time, the utility model saves energy, and the floor Kang has a large laying area and is located at the lowest part of the house, with a large heat dissipation area, the hot air can rise, and the whole indoor space can be heated, with good thermal efficiency.

\section{THE CHARACTERISTICS OF THE NEW RURAL HOUSES OF KOREAN NATIONALITY}

There are three main changes in the Korean folk houses in the old and new periods(Fig. 3). The changes from the old to the new are reflected in the following aspects:

\subsection{Heating mode}

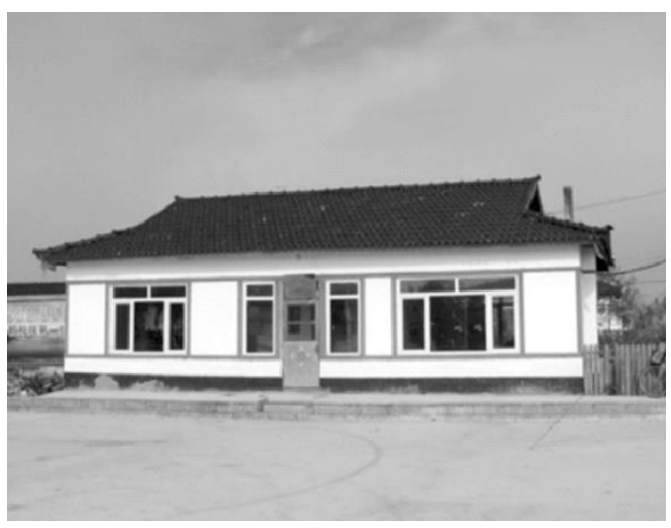

Figure 3. Appearance of new Korean dwellings

(1) Plane form: the kitchen space and living space are set separately, the functional zoning is more reasonable and clear, and the comfort and privacy are improved.

(2) Building materials: brick and cement are used to replace thatch, Adobe and other building materials, which improves the overall stiffness and stability of the building, makes it possible to increase the building area, improves the ability to resist wind and rain erosion, and also improves the indoor comfort.

(3) Building appearance: the roof form used to be restricted by the material, and the slope was small. The newly-built residential buildings mostly used the Xieshan mountain, which had a larger slope and was conducive to drainage. At the same time, the end of the roof is also decorated with images of immortals and animals with Korean characteristics; The size of doors and windows can also be enlarged due to the improvement of loadbearing structural materials, which is conducive to indoor ventilation and lighting.

\section{SUSTAINABLE DEVELOPMENT DESIGN STRATEGY}

\subsection{Optimize the layout}

(1) According to the living habits of the Korean people, the functional zoning of the building plane is 
carried out scientifically, and the living space, bedroom, toilet, food, storage and other use spaces are effectively organized. The partition wall instead of sliding door is used to separate the functional space. The dynamic and static partition, clean partition, and privacy are also ensured, which makes the use of the space more reasonable. Keep the use of Kang in traditional residence, and give full play to its advantages of energy saving and high efficiency in winter heating.

(2) Increasing the depth of the building, reducing the shape coefficient of the building, connecting the two households and arranging the storage space at both ends can reduce the "cold mountain", which can reduce the heat loss of the building in winter, improve the thermal efficiency, save energy and reduce pollution.

(3) Emphasis on the role of orientation on the plane layout, as far as possible along the North-South layout,

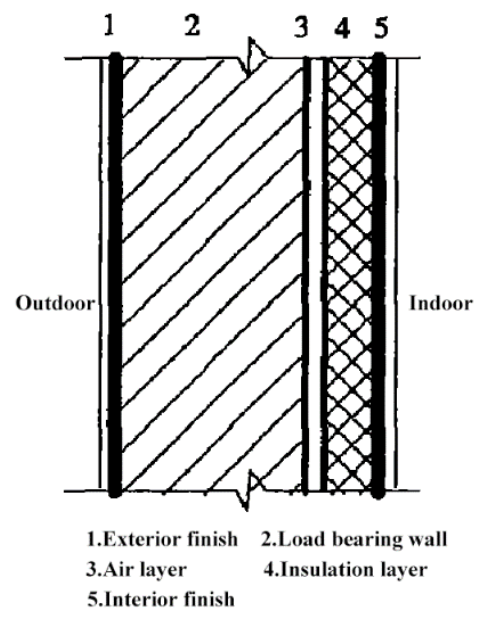

(a)Internal insulation composite wall the living room, bedroom and other main functional rooms are arranged in the south, in order to obtain sufficient sunshine and daylighting, and the kitchen, storage and other auxiliary space is arranged in the north, which is conducive to better indoor thermal environment in winter, saving energy.

\subsection{Improve the thermal insulation performance of building envelope}

The winter in Yanbian area is long and cold, and the heat loss of buildings is large, which is mainly consumed by the exterior wall, roof, door and window gaps and other exterior enclosure components. Therefore, the energy-saving and thermal insulation design of enclosure structure is the key to the sustainable ecological design of Korean residential buildings [5].

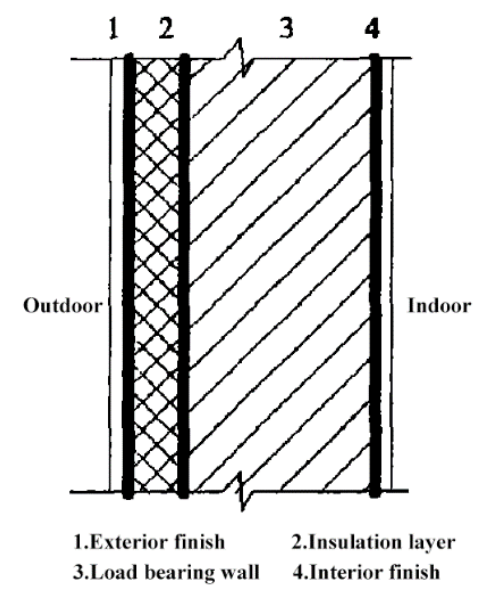

(b)External insulation composite wall

Figure 4. The internal insulation conforms to the wall structure

(1) Exterior wall design strategy: according to the characteristics of intermittent heating in winter of Korean residential buildings in Yanbian area, it is suggested that the exterior wall adopt internal thermal insulation composite wall structure (Fig. 4), which can use local materials, straw board as thermal insulation material, and cooperate with moisture-proof and waterproof design; Polystyrene foam can also be used as insulation layer.

(2) Roof design strategy: under the roof structure of the existing building, a layer of sawdust insulation layer with a thickness of $200 \mathrm{~mm}$ can be laid on the supporting structure, and then a tile roof waterproof layer can be laid.

(3) Door and window design strategy: the heat loss of doors and windows is mainly through the gap, cold wind pouring in, thus affecting the indoor thermal comfort in winter. The traditional wooden windows can be replaced by plastic steel windows with good sealing performance; On the premise of ensuring ventilation, reduce the area of the window opening fan, increase the area of the fixed fan, and reduce the cold air penetration of the gap; Double door can be made at the entrance, and cotton felt curtain can be added inside the outer door for thermal insulation.

\subsection{Reasonable setting of entrance position}

The entrance of the building plays a role of connecting the indoor and outdoor, which is the most affected position by the external environment in the building. Two corresponding doors are usually arranged in Korean residential buildings. When they are opened at the same time, it is conducive to indoor ventilation in summer, but it will become an important part of heat loss in winter, reducing indoor temperature and affecting comfort. Therefore, special energy-saving and thermal insulation design should be carried out at the entrance, The following measures can be taken:

(1) At the same time, the door is opened laterally to avoid facing the dominant wind direction in winter. 
(2) The outer side of the entrance is wrapped with a wind barrier, and the height and width are larger than the outer door to block the cold wind.

(3) Add a door, double door spacing 300-400mm, add a layer of shelter to ensure that the cold wind will not directly blow into the room, play the role of insulation.

\section{CONCLUSION}

Sustainable development is not only an important policy in China, but also an important guideline for rural construction in Yanbian area. According to different regions, different climate characteristics, different ethnic population composition and ecological resources composition, it is of great significance to adopt sustainable development strategy according to local conditions for environmental protection and energy conservation. Yanbian area, as a Korean inhabited area in China, has a large number of rural houses, wide distribution and representative architectural forms. Based on the characteristics of Yanbian Rural Korean residential design, comprehensive consideration of regional, draw on the experience of traditional residential construction, put forward to meet the sustainable development of the design strategy, has a certain guiding significance for the local green residential construction.

\section{ACKNOWLEDGMENTS}

This work was supported by Science and Technology Projects of the Education Department of Jilin Province (120210012).

\section{REFERENCES}

[1] China Academy of Building Sciences. (2010) JGJ26-95 Design Standard for Energy Efficiency of Civil Buildings (heating residential buildings). China Construction Industry Press, Beijing.

[2] Zhang, Y.H., (2019) Jilin folk houses. China Construction Engineering Press, Beijing.

[3] Tan, L.B., Tong, W., Ma,H. (2017) Study on the sustainable design of new rural vernacular dwellings of Yi nationality in Yunnan Province. Journal of Shandong Jianzhu University, 12: 500-505.

[4] Jin, R.X., Gong, X.F. (2020) Study on thermal insulation structure and thermal insulation optimization strategy of Korean folk houses in Yanbian area. Architecture and culture, 0: 234-236.

[5] Jin, H., Li, L.K., Chen, Q.F. (2018) Research and application of the attenuation index of the exterior envelope of the residential buildings in northern villages and towns. Journal of Harbin Institute of Technology, 33: 74-79. 